\title{
Evaluating and Enhancing Three-Dimensional Printing Service Providers for Rapid Prototyping Using the DEMATEL Based Network Process and VIKOR
}

\author{
Shin Liao, ${ }^{1}$ Ming-Jenn Wu, ${ }^{2}$ Chi-Yo Huang, ${ }^{2}$ Yu-Sheng Kao, ${ }^{2}$ and Teng-Hsiang Lee ${ }^{2}$ \\ ${ }^{1}$ Department of Graphic Arts and Communications, National Taiwan Normal University, Taipei 106, Taiwan \\ ${ }^{2}$ Program of Technology Management, Department of Industrial Education, National Taiwan Normal University, \\ Taipei 106, Taiwan
}

Correspondence should be addressed to Chi-Yo Huang; georgeh168@gmail.com

Received 6 October 2013; Revised 13 March 2014; Accepted 24 March 2014; Published 22 June 2014

Academic Editor: Ching-Ter Chang

Copyright (c) 2014 Shin Liao et al. This is an open access article distributed under the Creative Commons Attribution License, which permits unrestricted use, distribution, and reproduction in any medium, provided the original work is properly cited.

During the past years, the three-dimensional printing (3DP) has become a dominant rapid prototyping (RP) technology due to its very viable process in terms of cost, speed, and sales of related equipment. Nowadays, numerous 3DP based RP services are available. Because of the capability, service quality, and pricing of the services varies, how to select a suitable 3DP based RP service provider is very critical to the companies being engaged in new product developments. However, the issue was seldom studied. To resolve this problem, a hybrid multiple-criteria decision making (HMCDM) framework for evaluating and enhancing an appropriate 3DP based RP service provider based on the Decision Making Trial and Evaluation Laboratory (DEMATEL) based Network Process (DNP) as well as VIKOR (VIseKriterijumska Optimizacija I Kompromisno Resenje) was proposed. The analytic framework was verified as feasible by an empirical study based on the opinions being provided by 3DP and RP experts. The well-verified framework can serve as the basis of future evaluation, selection, and enhancement of 3DP based RP service providers.

\section{Introduction}

The three-dimensional (3D) printing (3DP) emerged recently as one of the most promising technologies to innovate the manufacturing technology and, furthermore, to revolutionize the industry. The 3DP implies possible reconfiguration of firms' strategies and operations along the supply and manufacturing, as well as retailing chains; in addition, the 3DP may imply even greater impacts [1]. Therefore, the Economist [2] heralds 3DP as "the manufacturing technology that will change the world." Later, a special report in the Economist by Markillie [3] further emphasized that the consequences of all the changes being introduced by the 3DP can amount to a third industrial revolution. Apparently, the 3DP is one of the most potential disruptive innovations, which may impact the manufacturing, the industry, and the social change significantly. Albeit the 3DP is a small evolutionary step from spraying toner on paper to putting down layers of something more substantial (such as plastic resin) until the layers add up to an object; by enabling a machine to produce objects of any shape, on the spot and as needed, the 3DP really is ushering in a new era [1]. The market for 3D printers and services is small but growing fast. Hutchings and Martin [4] summarized that the numbers of the overall market size are small compared to the global market in 2009 for 2D inkjet technologies, of the order of US\$50 billion (including hardware, media, and chemistry). McKinsey Global Institute [5] estimated that $3 \mathrm{DP}$ could generate economic impact of $\$ 230$ billion to $\$ 550$ billion per year by 2025, based on reduced cost and the value of customization; the largest source of potential impact would be from consumer uses, followed by direct manufacturing and the use of 3DP to create tools and molds.

As 3DP becomes more accessible on a global scale, consumers have begun to innovate across a diverse range of industries [6]. As summarized by Faktor [7] in Forbes, the global opportunities for 3D printing exist in many different industries (see Table 1). One of the major applications for the $3 \mathrm{DP}$ is the rapid prototyping (RP), a new forming process 
TABLE 1: 3DP global opportunities and applications.

\begin{tabular}{|c|c|c|c|}
\hline \multirow{2}{*}{ Printer readiness } & \multicolumn{3}{|c|}{ Target market } \\
\hline & Consumer & Small and medium enterprises & Corporations \\
\hline Needs more R\&D & & Organ replacement & $\begin{array}{l}\text { Furniture: } \$ 200 \text { B } \\
\text { Consumer electronics: } \$ 290 \text { B }\end{array}$ \\
\hline Nearing commercial use & Prepared food: \$23 B & $\begin{array}{l}\text { Science education } \\
\text { Bicycles: \$6 B } \\
\text { Guns and ammo: } \$ 11 \mathrm{~B} \\
\text { Global apparel: } \$ 1 \mathrm{~T} \\
\end{array}$ & $\begin{array}{l}\text { Life science R\&D: } \\
\text { Power tools: } \$ 22 \mathrm{~B} \\
\text { Home building and } \\
\text { improvements: } \$ 680 \mathrm{~B}\end{array}$ \\
\hline In use & $\begin{array}{l}\text { Animation and gaming: } \\
\$ 122 \mathrm{~B} \\
\text { Crafts and hobby: } \$ 30 \mathrm{~B}\end{array}$ & $\begin{array}{l}\text { Medical prosthetics: \$18 B } \\
\text { Tchotchkes: \$16 B }\end{array}$ & $\begin{array}{l}\text { Industrial } \mathrm{R} \& \mathrm{D} \text { (for } \\
\text { prototyping): } \$ 23 \mathrm{~B} \\
\text { Aircraft and defense R\&D: } \$ 9 \mathrm{~B}\end{array}$ \\
\hline
\end{tabular}

Source: [7].

and principle which is one of the important breakthroughs of recent technological progress in the manufacturing industry [8] emerging in 1988 [8]. The RP technology converts the three-dimensional (3D) computer data being provided by dedicated file format directly to physical model, layer by layer, with a high degree of accuracy [9] and thus can produce prototypes with capricious shapes rapidly with a high degree of details and at a lower cost than conventional prototyping techniques $[10,11]$. Nowadays, the RP is used in a variety of industries to describe a process for quickly creating a system or part representation before final release or commercialization [12] due to the significant benefit of RP including zero tool costs, reduced lead times, and considerable gains in terms of freedom in product design and production schedules [13]. The 3D printers currently have an approximately $12 \%$ share of the overall $\mathrm{RP}$ and manufacturing market of around US\$1 billion [4]. The predicted growth is not startling, largely coming from an increased market share taken from competing technologies and being limited by the lack of foreseen technology innovations [4].

The 3DP based RP arrived to the forefront as a very viable process in terms of cost and speed, and sales of related equipment have increased significantly compared with other RP machines [14]. These 3DP based RP devices were developed and are still seen, mostly as a "concept modeler" [9]. The flexibility 3DP offering is outstanding in many aspects. The scalability of the 3DP technique enables manufacturing of large specimens in the meter range [15] as well as small specimens of a few $\mathrm{mm}[15,16]$. The freedom to build up any geometry is limited only by the precision to the method and the surface quality of the parts [17]. Consequently, 3DP based RP has been extensively applied to various domains. Further, since the 3DP based RP equipment is becoming more competitive in comparison with traditional manufacturing techniques in terms of price, speed, reliability, and cost of use, the industrial applications emerged rapidly and thus the revenue boomed explosively; in addition, a new industry is emerging to create software to enable more effective use of the technology [18].

The 3DP started to become established as a manufacturing technology in the late 1970s [19]. In the past, no small business could have afforded to buy an industrialscale $3 \mathrm{D}$ printer and pay for enough computing power to run industrial design software [20]. However, the situation is changing. The cost of 3DP machines is falling to the point where private individuals in the developed world may easily own them [19]. In the 3DP market, firms are buying up the printers and then contracting out printing services to firms that need rapid prototyping [21]. Therefore, numerous 3DP based RP technology service providers are available now. Small business can provide design engineering, prototyping and 3DP services [20]. Though 3DP services have become widely available, the capability, service quality, price, and so forth vary. Thus, how to select a suitable 3DP based RP service provider is essential. However, the issue was seldom studied. How 3DP based RP service providers can be assessed has become the most critical issue in the commercialization of novel products. Moreover, how the services of a 3DP based RP service provider can be enhanced can be further addressed by those in both engineering and marketing.

This research intends to adopt a framework based on hybrid multiple-criteria decision making (HMCDM) methods for the assessment of an appropriate 3DP based RP service provider. First, the literature related to prototyping, $\mathrm{RP}$, and the 3DP based RP will be reviewed. This literature will serve as a basis for the HMCDM framework development for suitable 3DP based RP service providers. Then, the Decision Making Trial and Evaluation Laboratory (DEMATEL) will be used for configuring the structure to the decision framework. The DEMATEL based network process (DNP) will be leveraged for calculating the weights versus each criterion. Finally, the service providers can be ranked based on their compromise ranks by VIKOR (VIseKriterijumska Optimizacija I Kompromisno Resenje). The analytic framework can be used in selecting the most suitable 3DP based RP service providers. Experts from the Taiwanese information technology (IT) original design manufacturers (ODMs) as well as from a 3DP equipment and service provider were invited to evaluate possible 3DP based RP service providers. The evaluation results can be used to demonstrate the feasibility of the proposed framework. Meanwhile, the analytic framework can serve as the basis of future selections of 3DP based RP service providers.

The remainder of the paper is organized as follows. Section 2 is a review of the prototyping, RP, 3DP based RP, and technology evaluation and assessment. In Section 3, the 
research method, HMCDM, will be introduced to construct the decision framework. An empirical study for selecting the most suitable 3DP based RP will be detailed in Section 4 . Discussions will be presented in Section 5. Section 6 will conclude the paper with observations, conclusions, and recommendations for future studies.

\section{Evaluating a 3DP Based Fast Prototyping Service Provider}

In the following section, the literature on prototyping, RP, 3DP based RP, and the related services as well as technology evaluation will be reviewed. The literature review results will serve as the basis for the analytic framework development.

\subsection{Prototyping. A prototype is an important and vital part} of the product development process. In any design practice, the word "prototyping" is often not far from the things that the designers will be involved in. In most dictionaries, the definition of prototyping is the first or original example of something that has been or will be copied or developed; it is a model or preliminary version [22]. However, prototyping is often more than a designed car. It covers all kinds of prototypes used in the product development process, including objects like mathematical models, pencil sketches, foam models, and of course the functional physical approximation or exact replica of the product [22]. Therefore, prototyping is the process of realizing these prototypes. In general, the types of prototypes contain three aspects [22]: (1) the implementation of the prototype, from the entire product (system) itself to its subassemblies and components, (2) the form of the prototype, from a virtual prototype to a physical prototype, and (3) the degree of the approximation of the prototype, from very rough representation to exact replication of the product.

In product development, prototypes can be used for each development team to help the thinking, planning, experimenting, and learning processes whilst designing the product. Thus, prototyping often plays an important role in product development, which contains software development, goals of prototyping, horizontal and vertical prototyping, and the relationship between prototype and application system [23]. Chua et al. [22] defined the prototypes as five roles in product development process including (1) experimentation and learning, (2) testing and proofing, (3) communication and integration, (4) synthesis and integration, and (5) scheduling and makers.

The prototypes created with rapid prototyping technologies will serve most if not all of these roles. Being accurate physical prototypes that can be built with speed, many of these roles can be accomplished quickly, effectively, and together with other productively tools, for example, CAD, repeatedly with precision [24].

2.2. $R P$. The $\mathrm{RP}$ is a new forming process and principle which is one of the important breakthroughs of recent technological progress in the manufacturing industry. A fast prototyping method for the active vibration control system of
3D mechanical structures is presented. Today, they are used for a wide range of applications [25]. From the emergence of the first RP system (SLA) in 1988, numerous RP systems with more than 20 kinds of processes were in operation around the world. In the early days of RP, the automotive and aerospace industries dominated the RP application. But this is no longer the case as RP has spread into many other industries. It shows how fast the RP technology is developing. Digital design (CAD) and digital manufacturing have emerged to facilitate and accelerate product creation [26]. Nowadays, innovative solutions are now available and touchable with high technology, which is possible to thanks for fast prototyping and rapid technology. And in the future, more industries will benefit from this fast and wonderful technology.

The RP is such a proof of concept that was enabled in a short time interval between the conception of a proposal and the actual deployment of a functional product to serve [27]. The RP is also a highly integrated method and highly benefits from the other high technologies such as CAD and material technology. Digital CAD models directly control the RP process. And the process of computer-aided manufacturing is integrated together with the RP. Therefore, the RP, a really automated process, needs the least or no human intervenes. The process is with a high degree of flexibility. The material forming process is suitable for nonhomogeneous materials and gradient function or porosity. Compared to other manufacturing methods, RP is much more rapid than other methods from design to layout of the product, and the cost has no relation to the manufacturing quantities. Many new techniques emerged out, and a lot of measures were developed to promote the RP method. The technology has grown rapidly over the past two decades, and its advances are revolutionizing multidisciplinary fields intersecting engineering, physics, chemistry, microtechnology, and biotechnology [28].

2.3. The 3DP Based RP. Reviewing the history of 3DP, in the rapid rise of public interest, between 3DP in the early 2010's and home computing in the late 1970's, indeed, the two technologies share similar historical patterns in more than this. In both cases, the technology began with large, expensive machines sold to a highly selected group of industrial (or perhaps governmental) customers [29]; here, the parallel is between the mainframe computers of the 1960's and the expensive stereo-lithography devices of the late 1980's and early 1990's. In both cases, this early "mainframe" period was followed by a brief but significant phase in which the devices became available at lower cost to university labs and small businesses; in the case of computers, this brief period was characterized by "minicomputers" in the late 1960's and 1970 's, while in the case of 3DP, this period was characterized (in the past decade) by midsized workshop-scale 3D printers. And in both cases, the "minicomputer" phase preceded an explosive growth of experimental, accessible devices aimed initially at the hobbyist community and, still a bit later, at a wider audience of home users [29].

The definition of $3 \mathrm{DP}$ is somewhat inexact. While some experts in the field would restrict 3DP to units with inkjetbased print heads that create an object on a layer-by-layer 
basis, others would apply this term to office or consumer versions of rapid prototyping machines that are relatively of low cost and easy to use [30]. The word "rapid" relates to the ease of making a copy of an object due to the simplicity of writing a computer program that controls the object's shape. The term "prototyping" refers to this process as being too slow for use in mass production (in contrast to injection molding technologies that yield large quantities at low per-unit costs).

RP techniques are nowadays broadly used in the product development process. They allow for fast and low-cost manufacturing a small series of components directly from the component geometry parameterization stored in a 3D CAD (Computer Aided Design) model. The physical prototype allows for assessment of many aspects of functionality of the prototyped component in the developed product. For a review of various methods of rapid prototyping see [31]. However, there is one limitation of the common RP techniques which is the narrow choice of materials the prototype can be made of, limiting the scope of the material properties assigned to the prototype.

Innovative solutions are now available based on 3DP process, which can extend RC (rapid casting) to the lower costs with respect to previous technologies such as selective laser sintering of sand [32]. One of such technological solutions consists in investment casting starting from starch patterns produced on 3DP conceptual modelers. Another solution is Z Cast process, in which 3DP technology with the use of a ceramic material allows the production of complex cavities and cores, suitable for casting light alloys.

The RP process included slicing the part, planning the deposition parameters, and controlling the deposition process. 3DP can be applied in the RP because the systems can enable the haptic world to be rapidly developed in a simple environment, which can make non-computer-skilled users to create haptic 3D interactions [33].

2.4. Technology Evaluation. Technology evaluation is one of the most important core competencies for modern firms. The ability to evaluate technology is also essential for enhancing nations' wealth. Evaluation is an established branch of applied social sciences that started to emerge as a formal discipline in the 1930s [4]. The applications of technology evaluation that have emerged over the past three decades have grown, motivated by fierce international competitiveness, by increased environmental legislation and tort litigation, and by the emergence of the "corporate social responsibility" movement [34]. According to Drejer and Riis [35], technology is often the most visible part of competence; hence, the selection of technologies should be made very carefully. Distinctive technological competence provides the basis for superior firm performance [36] from the aspects of performing value chain analyses, identifying market advantages, avoiding being preempted in the marketplace, staying on the cutting edge, defining the cutting edge, maximizing the use of information, minimizing the product makespan, and, finally, achieving a competitive advantage in terms of cost, quality, or time to market [34]. Organizations engaged in research and technology development need to identify and explore emerging technological opportunities [37]. In a broader sense, at the national level, selecting and supporting key emerging technologies help countries to establish their strategic advantage in the international market [38]. Thus, appropriate technology evaluation and selection techniques enable a firm or a nation to identify the opportunities and establish its technological competencies [39].

Based on the classification by Henriksen [34], the most commonly seen technology evaluation techniques can be classified into nine categories: (1) economic analysis, (2) decision analysis, (3) systems engineering/systems analysis, (4) technological forecasting, (5) information monitoring, (6) technical performance analysis, (7) risk assessment, (8) market analysis, and (9) externalities/impact analysis. Among the major technology evaluation techniques, MCDM-based decision analysis approaches have been widely adopted. However, traditional MCDM approaches based on unrealistic assumptions on independencies between criteria cannot be feasible in the real world. Moreover, the MCDM framework based solely on the ANP (Analytic Network Process) can lack an appropriate method of structuring a decision, so the authors propose a hybrid, MCDM-based technology evaluation framework for selecting the most suitable disruptive innovation service provider and expanding the competences.

\section{Analytic Framework and Methods for Technology Assessment}

The analytical process for evaluating an appropriate 3DP based RP service provider for IT prototypes is initiated by establishing determinants using the modified Delphi method. Since any determinant derived by the modified Delphi may impact the others, the structure of the HMCDM problem will be derived using the DEMATEL. The weights being associated with each criterion will be derived by using the DNP. Finally, the VIKOR will be introduced to derive the compromise ranking of the alternatives. In summary, this evaluation framework consists of five main phases: (1) establishing determinants using the modified Delphi method, (2) building the structure of the network relation map (NRM) among determinants by using the DEMATEL, (3) calculating the priorities of every determinant by using the DNP, based on the structure of NRM derived by using the DEMATEL in (2), and finally (4) deriving compromise ranks of the 3DP based RP service providers by the VIKOR.

3.1. Modified Delphi Method. The Delphi method was designed by Dalkey and Helmer [40]. After the Delphi method, Murry and Hammons [41] tried to identify issues and problems that were collected from a group of technology education professionals using the modified Delphi technique. The modified Delphi simplified the step of conducting the first round of a survey and replaced the conventionally adopted open style survey [42]. The purpose of the modified Delphi method is to save time and the experts can focus on research themes, eliminating the need for speculation on the open questionnaire, and to improve the response of the main topic $[42,43]$. Following, the introduction to Delphi and the 
modified Delphi methods are mainly based on the works by Jones and Hunter [44], Murry and Hammons [41], and Huang et al. $[45,46]$.

The primary objective of a Delphi inquiry is to obtain a consensus as a minimum of 75 percent agreement on any particular item at opinion from a group of respondents. Meanwhile, it is possible to develop consensus on a common core of management assessment criteria which, when combined with the institution-, unit-, and positionspecific criteria, can form a comprehensive management audit instrument.

The Delphi method originated in a series of studies conducted by the RAND Corporation in the 1950s [44]. The objective was to develop a technique to obtain the most reliable consensus from a group of experts [40]. Delphi may be characterized as a method for structuring a group communication process; so the process is effective in allowing a group of individuals, as a whole, to deal with a complex problem while researchers have developed variations of the method since its introduction [47]. Specific situations have included a round in which the participants meet to discuss the process and resolve any uncertainties or ambiguities in the wording of the questionnaire [44]. The Delphi method proceeds in a series of communication rounds, as follows.

Round 1: Either the relevant individuals are invited to provide opinions on a specific matter, based upon their knowledge and experience, or the team undertaking the Delphi expresses opinions on a specific matter and selects suitable experts to participate in subsequent questionnaire rounds; these opinions are grouped together under a limited number of headings, and statements are drafted for circulation to all participants through a questionnaire [44].

Round 2: Participants rank their agreement with each statement in the questionnaire; the rankings then are summarized and included in a repeat version of the questionnaire [44].

Round 3: Participants rerank their agreement with each statement in the questionnaire and have the opportunity to change their score, in view of the group's response; The rerankings are summarized and assessed for their degree of consensus: if an acceptable degree of consensus is obtained, the process may cease, with the final results then fed back to the participants; if it is not, this third round is repeated [44].

Murry and Hammons [41] modified the traditional Delphi technique by eliminating the first-round questionnaire containing unstructured questions. It is simplified to replace the conventionally adopted open style survey; doing so is commonly referred to as the modified Delphi method [42]. The modified Delphi technique is similar to the full Delphi in terms of procedure (i.e., a series of rounds with selected experts) and intent (i.e., to predict future events and to arrive at consensus). The major modification consists of beginning the process with a set of carefully selected items. These preselected items may be drawn from various sources including related competency profiles, synthesized reviews of the literature, and interviews with selected content experts.
The primary advantages of this modification to the Delphi is that it (a) typically improves the initial round response rate and (b) provides a solid grounding in previously developed work.

Additional advantages related to the use of the modified Delphi technique include reducing the effects of bias due to group interaction, assuring anonymity, and providing controlled feedback to participants [48, 49]. Brooks [50] noted that three mailings are usually sufficient in order to arrive at consensus.

3.2. The DNP Technique. The DNP, the DEMATEL technique combining with ANP, was proposed by Liu et al. [51] and Phillips-Wren et al. [52]. The DEMATEL technique was developed by the Battelle Geneva Institute (1) to analyze complex "real world problems" dealing mainly with interactive map-model techniques [53] and (2) to evaluate qualitative and factor-linked aspects of societal problems. DEMATEL has been successfully applied in many situations such as e-business model definitions [54, 55], policy definitions [45], and global manufacturing system optimization [56]. The ANP is general form of the analytic hierarchy process (AHP) [57] which has been used in multiple-criteria decision making (MCDM) to be able to release the restriction of hierarchical structure.

The DNP advanced the tradition decision making framework by manipulating the DEMATEL and the ANP individually in which a single round of survey of experts' opinions would be enough for resolving a decision making problem. In comparison to the traditional approach consisting of two rounds of expert opinion surveys, the DNP actually eases the survey procedure. The DEMATEL technique was developed with the belief that the pioneering and proper use of scientific research methods could help to illuminate specific and intertwined phenomena and contribute to the recognition of practical solutions through a hierarchical structure.

Combing the DEMATEL and ANP method, which had been reviewed in this section, the steps of this method can be summarized as follows.

Step 1. Calculate the direct-influence matrix by scores. Based on experts' opinions, evaluations are made of the relationships among elements (or variables/attributes) of mutual influence using a scale ranging from 1 to 5 , with scores representing "no influence" (1), "low influence" (2), "medium influence" (3), "high influence" (4), and "very high influence" (5). They are asked to indicate the direct effect they believe a factor will have on factor $j$, as indicated by $d_{i j}$. The matrix $\mathbf{D}$ of direct relations can be obtained.

Step 2. Normalize the direct-influence matrix based on the direct-influence matrix $\mathbf{D}$; the normalized direct relation matrix $\mathbf{N}$ is acquired by using

$$
\begin{array}{r}
\mathbf{N}=v \mathbf{D} ; \quad v=\min \left\{\frac{1}{\max _{i} \sum_{j=1}^{n} d_{i j}}, \frac{1}{\max _{j} \sum_{i=1}^{n} d_{i j}}\right\}, \\
i, j \in\{1,2, \ldots, n\} .
\end{array}
$$




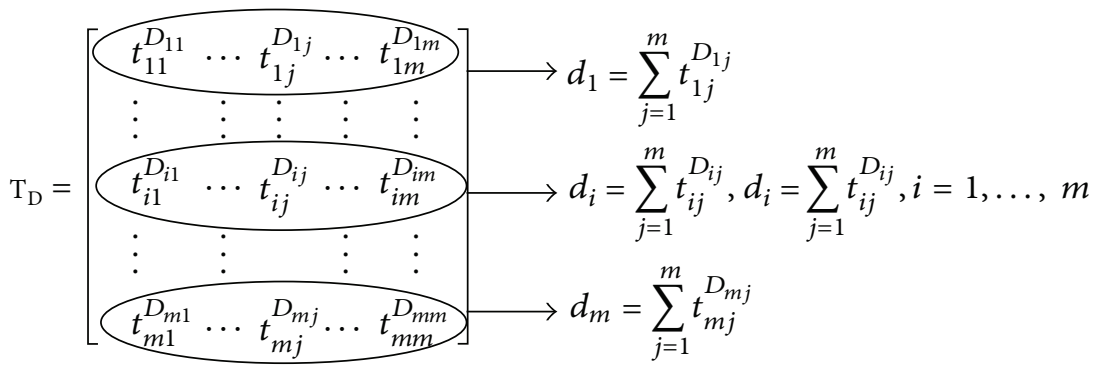

FiguRE 1

Step 3. Attain the total-influence matrix T. Once the normalized direct-influence matrix $\mathrm{N}$ is obtained, the total-influence matrix $\mathbf{T}$ of NRM can be obtained:

$$
\mathbf{T}=\mathbf{N}+\mathbf{N}^{2}+\cdots+\mathbf{N}^{k}=\mathbf{N}(\mathbf{I}-\mathbf{N})^{-1},
$$

where $k \rightarrow \infty$ and $\mathbf{T}$ is a total influence-related matrix; $\mathbf{N}$ is a direct-influence matrix and $\mathbf{N}=\left[x_{i j}\right]_{n \times n} ; \lim _{k \rightarrow \infty}\left(\mathbf{N}^{2}+\right.$ $\left.\cdots+\mathbf{N}^{k}\right)$ stands for an indirect-influence matrix and $0 \leq$ $\sum_{j=1}^{n} x_{i j}<1$ or $0 \leq \sum_{i=1}^{n} x_{i j}<1$ and only one $\sum_{j=1}^{n} x_{i j}$ or $\sum_{i=1}^{n} x_{i j}$ is equal to $1 \forall i, j$. So $\lim _{k \rightarrow \infty} \mathbf{N}^{k}=[\mathbf{0}]_{n \times n}$. The $(i, j)$ element of matrix $\mathbf{T}$ denotes the direct and indirect influences of factor $i$ on factor $j$.

Step 4. Analyze the result. In this stage, the row and column sums are separately denoted as $\mathbf{r}$ and $\mathbf{c}$ within the totalrelation matrix $\mathbf{T}$ through

$$
\begin{gathered}
\mathbf{T}=\left[t_{i j}\right], \quad i, j \in\{1,2, \ldots, n\}, \\
\mathbf{r}=\left[r_{i}\right]_{n \times 1}=\left[\sum_{j=1}^{n} t_{i j}\right]_{n \times 1}, \\
\mathbf{c}=\left[c_{j}\right]_{1 \times n}=\left[\sum_{i=1}^{n} t_{i j}\right]_{1 \times n},
\end{gathered}
$$

where the $\mathbf{r}$ and $\mathbf{c}$ vectors denote the sums of the rows and columns, respectively.

Suppose $r_{i}$ denotes the row sum of the $i$ th row of matrix $\mathbf{T}$. Then, $r_{i}$ is the sum of the influences dispatching from factor $i$ to the other factors, both directly and indirectly. Suppose that $c_{j}$ denotes the column sum of the $j$ th column of matrix. Then, $c_{j}$ is the sum of the influences that factor $i$ is receiving from the other factors. Furthermore, when $i=j$ (i.e., the sum of the row sum and the column sum) $\left(r_{i}+c_{i}\right)$ represents the index representing the strength of the influence, both dispatching and receiving, $\left(r_{i}+c_{i}\right)$ is the degree of the central role that factor $i$ plays in the problem. If $\left(r_{i}-c_{i}\right)$ is positive, then factor $i$ primarily is dispatching influence upon the strength of other factors; and if $\left(r_{i}-c_{i}\right)$ is negative, then factor $i$ primarily is receiving influence from other factors $[45,58]$. Therefore, a causal graph can be achieved by mapping the dataset of $\left(r_{i}+\right.$ $s_{i}, r_{i}-s_{i}$ ) providing a valuable approach for decision making (see [52]).

Now we call the total-influence matrix $\mathbf{T}_{\mathbf{C}}=\left[t_{i j}\right]_{n x n}$ obtained by criteria and $\mathbf{T}_{\mathbf{D}}=\left[t_{i j}^{D}\right]_{n \times n}$ obtained by dimensions (clusters) from $\mathbf{T}_{\mathbf{C}}$. Then we normalize the ANP weights of dimensions (clusters) by using influence matrix $\mathbf{T}_{\mathbf{D}}$ (see Figure 1).

Step 5. The original supermatrix of eigenvectors is obtained from the total-influence matrix $\mathbf{T}=\left[t_{i j}\right]$, for example, $D$ values of the clusters in matrix $\mathbf{T}_{\mathbf{D}}$, as (6), where if $t_{i j}<D$, then $t_{i j}^{D}=0$ else $t_{i j}^{D}=t_{i j}$, and $t_{i j}$ is in the total-influence matrix $\mathbf{T}$. The total-influence matrix $\mathbf{T}_{\mathbf{D}}$ needs to be normalized by dividing by the following formula. Then, we could normalize the total-influence matrix and represent it as $\mathbf{T}_{\mathbf{D}}$ :

$$
\begin{aligned}
\mathbf{T}_{\mathbf{D}} & =\left[\begin{array}{ccccc}
\frac{t_{11}^{D_{11}}}{d_{1}} & \cdots & \frac{t_{1 j}^{D_{1 j}}}{d_{1}} & \cdots & \frac{t_{1 m}^{D_{1 m}}}{d_{1}} \\
\vdots & \vdots & \vdots & \vdots & \vdots \\
\frac{t_{i 1}^{D_{i 1}}}{d_{i}} & \cdots & \frac{t_{i j}^{D_{i j}}}{d_{i}} & \cdots & \frac{t_{i m}^{D_{i m}}}{d_{i}} \\
\vdots & \vdots & & \vdots & \vdots \\
t_{m 1}^{D_{m 1}} & \cdots & t_{m j}^{D_{m j}} & \cdots & \frac{t_{m m}^{D_{m m}}}{d_{m}} \\
\frac{d_{m}}{d_{m}} & \cdots & & d_{m}
\end{array}\right] \\
= & {\left[\begin{array}{ccccc}
\alpha_{11}^{D_{11}} & \cdots & \alpha_{1 j}^{D_{1 j}} & \cdots & \alpha_{1 m}^{D_{1 m}} \\
\vdots & \vdots & \vdots & \vdots & \vdots \\
\alpha_{i 1}^{D_{i 1}} & \cdots & \alpha_{i j}^{D_{i j}} & \cdots & \alpha_{i m}^{D_{i m}} \\
\vdots & \vdots & & \vdots & \vdots \\
\alpha_{m 1}^{D_{m 1}} & \cdots & \alpha_{m j}^{D_{m j}} & \cdots & \alpha_{m m}^{D_{m m}}
\end{array}\right], }
\end{aligned}
$$

where $\alpha_{i j}^{D_{i j}}=t_{i j}^{D_{i j}} / d_{i}$. This research adopts the normalized total-influence matrix $\mathbf{T}_{\mathbf{D}}$ (here after abbreviated to "the normalized matrix") and the unweighted supermatrix $\mathbf{W}$ using (7) shows theses influence level values as the basis of the normalization for determining the weighted supermatrix: 


$$
\mathbf{W}^{*}=\left[\begin{array}{ccccc}
\alpha_{11}^{D_{11}} \times \mathbf{W}_{\mathbf{1 1}} & \alpha_{21}^{D_{21}} \times \mathbf{W}_{\mathbf{1 2}} & \cdots & \cdots & \alpha_{m 1}^{D_{m 1}} \times \mathbf{W}_{\mathbf{1 m}} \\
\alpha_{12}^{D_{12}} \times \mathbf{W}_{\mathbf{2 1}} & \alpha_{22}^{D_{22}} \times \mathbf{W}_{\mathbf{2 2}} & \cdots & \cdots & \vdots \\
\vdots & \cdots & \alpha_{j i}^{D_{j i}} \times \mathbf{W}_{\mathbf{i j}} & \cdots & \alpha_{m i}^{D_{m i}} \times \mathbf{W}_{\mathbf{i m}} \\
\vdots & \vdots & \vdots & \vdots & \vdots \\
\alpha_{1 m}^{D_{1 m}} \times \mathbf{W}_{\mathbf{m} \mathbf{1}} & \alpha_{2 m}^{D_{2 m}} \times \mathbf{W}_{\mathbf{m} \mathbf{2}} & \cdots & \cdots & \alpha_{m m}^{D_{m m}} \times \mathbf{W}_{\mathbf{m m}}
\end{array}\right]
$$

Step 6. Limit the weighted supermatrix by raising it to a sufficiently large power $k$, as (7), until the supermatrix has converged and become a long-term stable supermatrix to get the global priority vectors or called ANP weights:

$$
\lim _{k \rightarrow \infty}\left(\mathbf{W}^{*}\right)^{k}
$$

According to the definition by Lu et al. [59], the significant confidence level can be calculated by

$$
\frac{1}{n^{2}} \sum_{i=1}^{n} \sum_{j=1}^{n} \frac{\left|t_{i j}^{p}-t_{i j}^{p-1}\right|}{t_{i j}^{p}} \times 100 \%,
$$

where $n$ denotes the number of criteria, $p$ denotes the number of experts, and $t_{i j}^{p}$ is the average influence of criterion $i$ on criterion $j$.

3.3. VIKOR. While solving a complex decision making problem by using an MCDM framework, the alternatives can be ranked and the best one can be selected based on the concept of compromise solution which was developed by Yu [60] and Zeleny and Cochrane [61]. The compromise solution is a feasible solution, which is the closest to the ideal, and a compromise means an agreement established by mutual concessions [62]. A compromise solution for a problem with conflicting criteria can help the decision makers to reach a final decision [62]. The VIKOR method was introduced as one applicable technique to implement within MCDM [63]. In comparison to one of the most well-known traditional compromise ranking methods, TOPSIS, which determine a solution with the shortest distance from the ideal solution and the farthest distance from the negative-ideal solution $[64,65]$, the VIKOR can prohibit the problem of not considering the relative importance of these distances. Following, based on Opricovic and Tzeng [62] and Tzeng and Huang [56], the procedures for VIKOR are introduced as a basis for this hybrid MCDM framework. The VIKOR is applied here to derive the optimal alternative (strategy) with the shortest distance from the ideal solution.

Assume the alternatives can be denoted as $A_{1}, A_{2}, \ldots$, $A_{l}, \ldots, A_{m}$. The rating (performance score) of the $j$ th criterion is denoted by $f_{l j}$ for alternative $A_{l}, w_{j}$ is the weight of the $j$ th criterion, expressing the relative importance of the criteria, where $j=1,2, \ldots, n$, and $n$ is the number of criteria.
The VIKOR method began with the following form of $L_{p^{-}}$ metric:

$$
L_{l}^{p}=\left\{\sum_{j=1}^{n}\left[\frac{w_{j}\left(\left|f_{j}^{*}-f_{l j}\right|\right)}{\left|f_{j}^{*}-f_{j}^{-}\right|}\right]^{p}\right\}^{1 / p},
$$

where $1 \leq p \leq \infty ; l=1,2, \ldots, m$; weight $w_{j}$ is derived using the ANP according to the NRM based on the DEMATEL method. The VIKOR method also uses $L_{l}^{p=1}$ (as $S_{l}$ ) and $L_{l}^{p=\infty}$ $\left(\right.$ as $\left.Q_{l}\right)$ to formulate the ranking measure $[63,66-70]$ :

$$
\begin{gathered}
S_{l}=L_{l}^{p=1}=\sum_{j=1}^{n}\left[\frac{w_{j}\left(\left|f_{j}^{*}-f_{l j}\right|\right)}{\left|f_{j}^{*}-f_{j}^{-}\right|}\right], \\
Q_{l}=L_{l}^{p=\infty}=\max _{j}\left\{\frac{w_{j}\left(\left|f_{j}^{*}-f_{l j}\right|\right)}{\left|f_{j}^{*}-f_{j}^{-}\right|} \mid j=1,2, \ldots, n\right\} .
\end{gathered}
$$

The compromise solution $\min _{l} L_{l}^{p}$ will be chosen because its value is closest to the ideal/aspired level. In addition, when $p$ is small, the group utility is emphasized (e.g., $p=1$ ) and as $p$ increases to $p=\infty$, the individual maximal regrets/gaps receive more importance, as shown by Yu [60, 71]. Therefore, $\min _{l} S_{l}$ emphasizes the maximum group utility, whereas $\min _{l} Q_{l}$ emphasizes selecting the minimum of the maximum individual regrets.

Based on the above concepts, the compromise ranking algorithm VIKOR has the following steps.

Step 7. Normalize the original rating matrix. In this step, we determine the best $f_{j}^{*}$ and the worst $f_{j}^{-}$values of all criterion functions, $j=1,2, \ldots, n$. Assume the $j$ th function represents a benefit: $f_{j}^{*}=\max _{l} f_{l j}$ (or setting an aspired level) and $f_{j}^{-}=$ $\min _{l} f_{l j}$ (or setting a tolerable level). Alternatively, assume the $j$ th function represents a cost: $f_{j}^{*}=\min _{l} f_{l j}$ (or setting an aspired level) and $f_{j}^{-}=\max _{l} f_{l j}$ (or setting a tolerable level). Moreover, an original rating matrix is transformed into a normalized weight-rating matrix with the following formula:

$$
r_{l j}=\frac{\left|f_{j}^{*}-f_{l j}\right|}{\left|f_{j}^{*}-f_{j}^{-}\right|} .
$$

Step 8. Compute the values $S_{l}$ and $Q_{l}, l=1,2, \ldots, m$, using the relations $S_{l}=\sum_{j=1}^{n} w_{j} r_{l j}$ and $Q_{l}=\max _{j}\left\{r_{l j} \mid j=\right.$ 
$1,2, \ldots, n\}$, where $S_{l}$ and $Q_{l}$ show the mean of group utility and maximal regret, respectively. In the traditional VIKOR method, $Q_{l}$ is represented as $\max _{j}\left\{w_{j} r_{l j} \mid j=1,2, \ldots, n\right\}$, which implies group utility is more important than maximal regret. Since $Q_{l}$ is only a part of $S_{l}, S_{l}$ is unquestionably more than $Q_{l}$. Therefore, $S_{l}$ is emphasized more than $Q_{l}$ in the traditional VIKOR method. However, the maximal regret is also very important in practice and is usually taken into account in order to improve it. Therefore, in order to balance $S_{l}$ and $Q_{l}$,

$$
Q_{l}=\max _{j}\left\{r_{l j} \mid j=1,2, \ldots, n\right\}
$$

is used instead of the traditional VIKOR $Q_{l}$.

Step 9. Compute the index values $R_{l}, l=1,2, \ldots, m$, using the relation $R_{l}=v\left(S_{l}-S^{*}\right) /\left(S^{-}-S^{*}\right)+(1-v)\left(Q_{l}-Q^{*}\right) /\left(Q^{-}-\right.$ $\left.Q^{*}\right)$, where $S^{*}=\min _{l} S_{l}, S^{-}=\max _{l} S_{l}, Q^{*}=\min _{l} Q_{l}, Q^{-}=$ $\max _{l} Q_{l}$ (here, we can also set the best value to 0 and the worst value to 1 ), and $0 \leq v \leq 1$, where $v$ is introduced as a weight for the strategy of maximum group utility, whereas $1-v$ is the weight of the individual regret.

Step 10. Rank the alternatives according to the value of $S_{l}$, $Q_{l}$, and $R_{l}$, with the decreasing order, for $l=1,2, \ldots, m$. A compromise solution, the alternative $\left(A^{(1)}\right)$, can be proposed based on the ranking of the the measure, $\min \left\{R_{l} \mid l=\right.$ $1,2, \ldots, m\}$, if the following two conditions are satisfied:

(C1) acceptable advantage: $R\left(A^{(2)}\right)-R\left(A^{(1)}\right) \geq 1 /(m-$ $1)$, where $A^{(2)}$ is the alternative with second position in the ranking list by $R$ and $m$ is the number of alternatives,

(C2) acceptable stability in decision making: alternative $A^{(1)}$ must also be the best ranked by $S_{l}$ or/and $Q_{l}, l=$ $1,2, \ldots, m$.

A set of compromise solutions is proposed if one of the conditions is not satisfied. The set of compromise solutions consists of (1) alternatives $A^{(1)}$ and $A^{(2)}$ if only condition $\mathrm{C} 2$ is not satisfied and (2) alternatives $A^{(1)}, A^{(2)}, \ldots, A^{(M)}$ if condition $\mathrm{C} 1$ is not satisfied. $A^{(M)}$ is determined by the relation $R\left(A^{(M)}\right)-R\left(A^{(1)}\right)<1 /(m-1)$ for maximum $M$ (the positions of these alternatives are close).

The compromise ranking method (VIKOR method) determines the compromise solution; the obtained compromise solution is acceptable to the decision-makers because it provides a maximum group utility of the majority (represented by $\min S$ ) and a minimum individual maximal regret of the opponent (represented by min Q). The model uses DNP procedures in Section 3.2 to obtain the weights of criteria with dependence and feedback and uses the VIKOR method to obtain the compromise solution.

\section{Empirical Study}

The introductions of 3DP in prototyping of industrial research and development in general and the RP of novel IT products in special are not new. According to the recent article by Faktor [7] which appeared in Forbes, the 3DP technology has been matured for uses in prototyping of industrial research and development; the market size is around \$23
TABLE 2: Background of experts.

\begin{tabular}{lcccc}
\hline No. & Industry & Work experience & Position & Education \\
\hline 1 & IT ODM & Above 20 & Manager & Diploma \\
2 & IT ODM & Above 20 & Manager & B.A. \\
3 & IT ODM & Above 20 & Manager & Diploma \\
4 & IT ODM & Above 20 & Manager & M.S. \\
5 & IT ODM & Above 20 & Manager & Diploma \\
6 & IT ODM & $15 \sim 20$ & Manager & B.A. \\
7 & IT ODM & $15 \sim 20$ & Manager & B.A. \\
8 & IT ODM & $15 \sim 20$ & Manager & B.A. \\
9 & IT ODM & $15 \sim 20$ & Manager & Diploma \\
10 & IT ODM & $15 \sim 20$ & Manager & Diploma \\
11 & IT ODM & $15 \sim 20$ & Manager & B.A. \\
12 & IT ODM & $15 \sim 20$ & Manager & Diploma \\
13 & IT ODM & $15 \sim 20$ & Manager & Diploma \\
14 & IT ODM & $15 \sim 20$ & Manager & Diploma \\
15 & IT ODM & $15 \sim 20$ & Manager & M.S. \\
16 & 3DP ESP & $15-20$ & Director & B.A. \\
\hline
\end{tabular}

Remark: ${ }^{*} \mathrm{EQSP}$ stands for the equipment and service provider.

Billion. For years, the IT mechanical engineers used the 3DP for fabricating prototypes in the very early stages of new product development. Then, the prototypes were further refined by the CNC milling machine by removing small chunks until the desired part was there. The refined prototype can be used to demonstrate the mechanism when the designs have not been finalized.

3DP components are typically used as "proof of concept" models [72]. The comparatively high speed and low operational cost of 3DP mean that a large number of models can be produced during the product development phase [73]. Designers can go through several iterations aided by physical samples to evaluate each concept $[73,74]$. The models are used to further enhance communication between engineers and nonengineering departments during the design phase to help with error detection. Apparently, 3DP based RP services are very critical for the name branded IT products in the new product development process in general and the concept design and testing stages and in particular [73].

Due to the importance of the 3DP services on new IT product development, an empirical study based on a leading IT original design manufacturer's selections of 3DP based RP service provider will be demonstrated to verify the proposed analytic framework.

Based on the literature review results, sixteen criteria were derived. Then, 15 mechanical managers (Table 2) from leading Taiwanese ODMs and 1 sales director from a 3DP equipment and service provider were invited to service as experts and provide opinions for deriving evaluation criteria for the 3DP based RP service providers. All the senior mechanical managers have experiences in evaluating and selecting the 3DP based RP molds. Further, the sales director from the 3DP equipment and service provider is very familiar with 3DP applications in industries. The structure of the 
TABLE 3: Candidate aspects and criterion for 3DP based RP service providers.

\begin{tabular}{|c|c|c|}
\hline Aspect & Criterion & Description \\
\hline \multirow{4}{*}{$\begin{array}{l}\text { Generic } \\
\text { management } \\
\text { capability }\end{array}$} & CPM & $\begin{array}{l}\text { Communication capabilities of } \\
\text { project managers }\end{array}$ \\
\hline & MHL & Mold history list maintenance \\
\hline & PLG & Product logistic management \\
\hline & MPD & Mass production delivery \\
\hline \multirow{4}{*}{$\begin{array}{l}\text { Technology } \\
\text { capability }\end{array}$} & RPE & Related product experiences \\
\hline & RDS & R\&D resource availability \\
\hline & CADM & $\begin{array}{l}\text { Computer aided design and } \\
\text { manufacturing }\end{array}$ \\
\hline & PNT & $\begin{array}{l}\text { The plan for new technology } \\
\text { introductions }\end{array}$ \\
\hline \multirow{4}{*}{$\begin{array}{l}\text { Quality } \\
\text { management } \\
\text { capability }\end{array}$} & TQS & Total quality management system \\
\hline & FCI & FAI/Cpk implement control \\
\hline & PME & $\begin{array}{l}\text { Precision manufacturing } \\
\text { equipment }\end{array}$ \\
\hline & PMT & Precision measurement tool \\
\hline \multirow{4}{*}{$\begin{array}{l}\text { Flexibility with } \\
\text { responsiveness }\end{array}$} & QIT & Quotation on time \\
\hline & FAE & $\begin{array}{l}\text { Field application engineering } \\
\text { capability }\end{array}$ \\
\hline & MDC & $\begin{array}{l}\text { Capabilities to realize design } \\
\text { changes by customers }\end{array}$ \\
\hline & FUS & $\begin{array}{l}\text { Provision of free, urgency, and } \\
\text { shortage samples }\end{array}$ \\
\hline
\end{tabular}

decision framework and the weights being associated with the criteria will also be derived based on the experts' opinions.

In this Section, the criteria for evaluating of 3DP based RP service providers will first be derived by using the modified Delphi method in Section 4.1. Then, in Section 4.2, the decision structure and the weights being associated with the criteria will be derived by using the DNP based on the 16 experts' opinions. In Section 4.3, 6 3DP based RP service providers will be ranked by using the VIKOR method. The evaluation results will also serve as the basis for improving the competences of the service providers.

4.1. Criteria Derivations by Delphi. According to the literature review results, 4 possible aspects and 16 criteria were summarized. The aspects include the generic management capability (MC), the technology capability (TC), the quality management capability (QC), and the flexibility with responsiveness (FRC). The generic management capability aspect includes the communication capability of project managers (CPM), the mold history list maintenance (MHL), the product logistic management (PLG) capability, and the mass production delivery (MPD) capability. The technology capability aspect includes related product experiences (RPE), the R\&D resource availability (RDS), the computeraided design and computer-aided manufacturing capability (CADM), and the plans for new technology introductions (PNT). The quality management aspect includes total quality management system (TQS), FAI/Cpk implement control
(FCI) capability, the precision of manufacturing equipment (PME), and perfection of the measurement tools (PMT). The aspects of flexibility with responsiveness include the quotation in time (QIT) capability, field application engineer capabilities (FAE), capabilities to meet design changes based on customer requests (MDC), and provisions of free, urgency, and shortage samples (FUS).

In order to derive the criteria for evaluating 3DP based RP service providers, the modified Delphi method was introduced at first. The experts being invited are those senior managers with more than 15 years of work experiences on mechanical design or 3DP services. According to the definition of modified Delphi method being introduced in Section 3.1, the agreement by $75 \%$ of the participant was taken as a threshold value of accepting a criterion. In Table 3, twelve criteria were agreed on by more than $75 \%$, while the percentage of PLG, RDS, CADM, and FCI was below $75 \%$, and so these twelve criteria are feasible to evaluate the mechanical manager's acceptance of a mold supplier. Criteria of mold supplier selection are shown in Table 3. The results being derived by the modified Delphi method based on opinions provided by 16 experts are demonstrated in Table 4.

4.2. An Empirical Study for Evaluating 3DP Based RP Service Providers by DNP. In order to derive the influence relationships between criteria and then derive the weights being associated with the criteria, the causal structure is first developed by using the DEMATEL. Then, the weights being associated with each criterion will be derived by using the DNP.

At first, the initial relation matrix is derived based on the definitions in Section 3.2 and experts' opinions. The initial relation matrix reveals the original influence relationships among these fifteen criteria. The experts are requested to indicate the direct influence of a factor $i$ on a factor $j$, as indicated by $a_{i j}$. Then, the matrix $\mathbf{N}$ is normalized based on the directinfluence matrix. The total-influence matrix $\mathbf{T}$ and the casual relationship are derived by using the equation introduced in Section 3. In matrix $\mathbf{T}$, the $(i, j)$ element $t_{i j}$ denotes the direct and indirect influences of factor $i$ on factor $j$.

Then, the casual relationship can be structured by the matrix T. The threshold is set at 0.141 , the third quartile in matrix $\mathbf{T}$, and the influence relationship is obtained as the matrix element $t_{i j}$ surpasses the threshold value, 0.141 . Finally, the casual relationship is drawn by matrix $\mathbf{T}$ in Figure 2 . The row and column sums are separately denoted as $r$ and $c$ within the total-relation matrix $\mathbf{T}$.

Following (4) and Figure 1 in Section 3, $\left(r_{i}+c_{i}\right)$ represents the index representing the strength of the influence, both dispatching and receiving, and $\left(r_{i}-c_{i}\right)$ is the degree of the central role that factor $i$ plays in the problem. If $\left(r_{i}-c_{i}\right)$ is positive, then factor $i$ primarily is dispatching influence upon the strength of other factors; and if $\left(r_{i}-c_{i}\right)$ is negative, then factor $i$ primarily is receiving influence from other factors. The $\left(r_{i}+c_{i}\right)$ and $\left(r_{i}-c_{i}\right)$ are demonstrated in Table 5 and Figure 2. In Figure 2, a causal graph is achieved by mapping the dataset of providing a valuable approach for decision making, and while the $\left(r_{i}-c_{i}\right)$ is demonstrated in the 


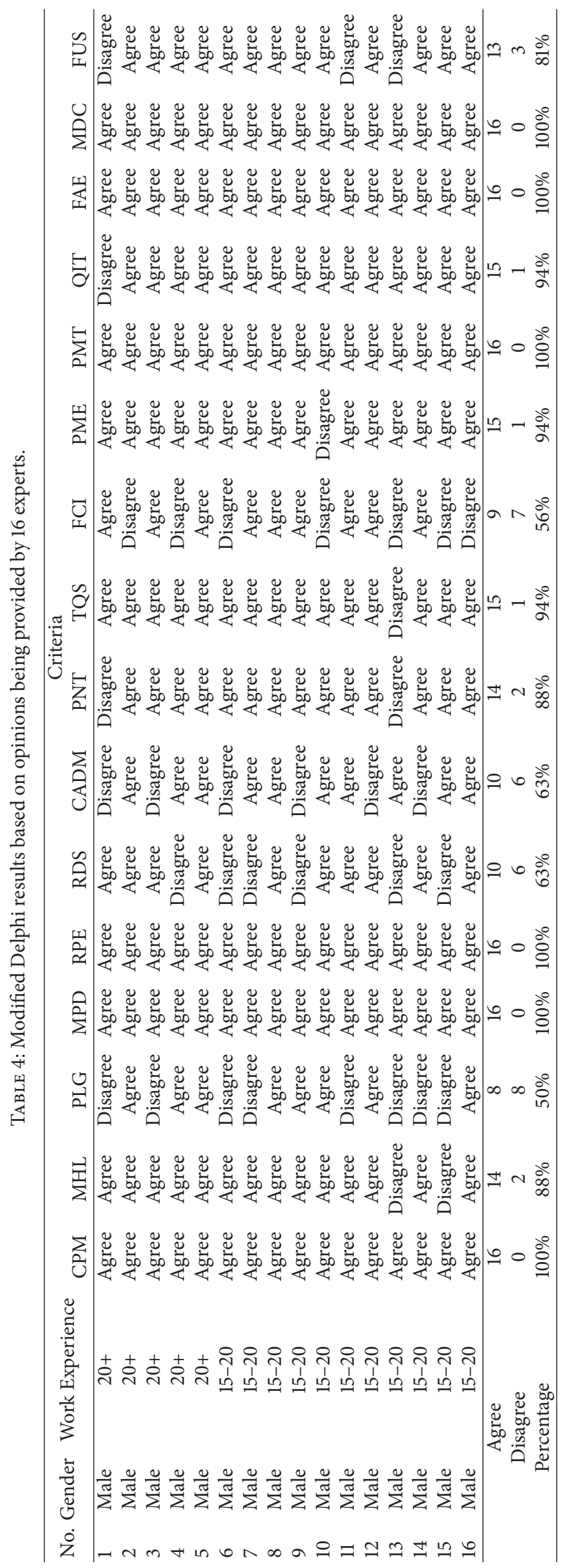


TABLE 5: $r_{i}+c_{i}, r_{i}-c_{i}$, weight and ranking versus each criterion.

\begin{tabular}{|c|c|c|c|c|c|c|c|c|}
\hline Dimensions & Criterion & Symbol & $r_{i}$ & $c_{i}$ & $r_{i}+c_{i}$ & $r_{i}-c_{i}$ & Weight & Ranking \\
\hline \multirow{3}{*}{$\begin{array}{l}\text { Generic management } \\
\text { capacity }\end{array}$} & $\mathrm{CPM}$ & $c_{1}$ & 1.941 & 1.641 & 3.581 & 0.300 & 0.094 & 1 \\
\hline & MHL & $c_{2}$ & 1.424 & 1.320 & 2.743 & 0.104 & 0.075 & 10 \\
\hline & MPD & $c_{3}$ & 1.662 & 1.617 & 3.279 & 0.045 & 0.092 & 3 \\
\hline \multirow{2}{*}{ Technology capacity } & RPE & $c_{4}$ & 1.724 & 1.518 & 3.242 & 0.205 & 0.087 & 5 \\
\hline & PNT & $c_{5}$ & 1.381 & 1.314 & 2.695 & 0.066 & 0.075 & 11 \\
\hline \multirow{3}{*}{$\begin{array}{l}\text { Quality management } \\
\text { capacity }\end{array}$} & TQS & $c_{6}$ & 1.578 & 1.637 & 3.215 & -0.059 & 0.093 & 2 \\
\hline & PME & $c_{7}$ & 1.359 & 1.508 & 2.867 & -0.149 & 0.086 & 6 \\
\hline & PMT & $c_{8}$ & 1.352 & 1.471 & 2.823 & -0.119 & 0.084 & 7 \\
\hline \multirow{4}{*}{$\begin{array}{l}\text { Flexibility with } \\
\text { responsiveness }\end{array}$} & QIT & $c_{9}$ & 1.169 & 1.281 & 2.450 & -0.112 & 0.072 & 12 \\
\hline & FAE & $c_{10}$ & 1.289 & 1.387 & 2.676 & -0.098 & 0.079 & 8 \\
\hline & MDC & $c_{11}$ & 1.451 & 1.568 & 3.020 & -0.117 & 0.089 & 4 \\
\hline & FUS & $c_{12}$ & 1.279 & 1.345 & 2.623 & -0.066 & 0.076 & 9 \\
\hline
\end{tabular}

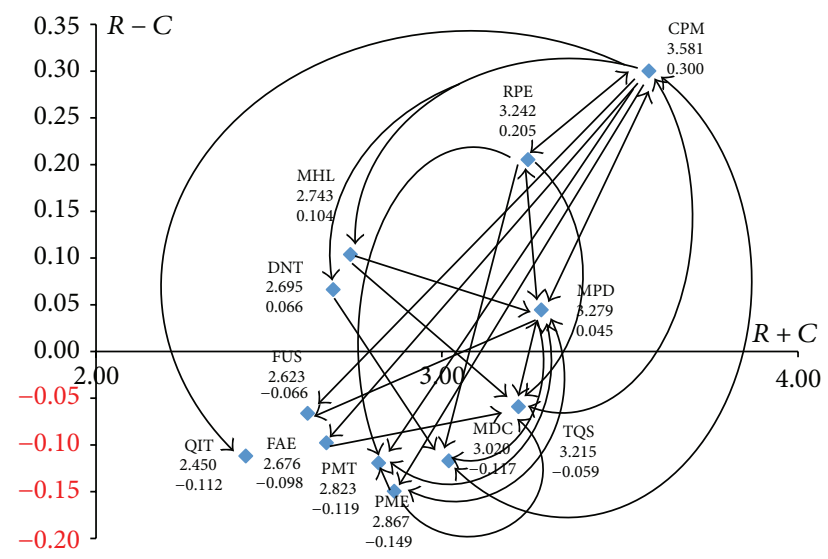

FIgURE 2: The causal diagram of criteria relationship.

vertical axis, the $\left(r_{i}+c_{i}\right)$ is in the horizontal axis. From the empirical result, the casual relationship further brings the criteria weight by using the DNP.

Forwards, this research adopts the normalized totalinfluence matrix $\mathbf{T}_{\mathbf{D}}$ and the unweight supermatrix $\mathbf{W}$ using (12) shows these influence level values as the basis of the normalization for determining the weighted supermatrix. Finally, limit the weighted supermatrix by raising it to a sufficiently large power $k$, as (7), until the supermatrix has converged and become a long-term stable supermatrix to get the global priority vectors or called criteria weights (refer to Table 4).

Finally, based on (8),

$$
\frac{1}{n^{2}} \sum_{i=1}^{n} \sum_{j=1}^{n} \frac{\left|t_{i j}^{p}-t_{i j}^{p-1}\right|}{t_{i j}^{p}} \times 100 \%=2.67 \%,
$$

which is smaller than $5 \%$. The significant confidence level is 97.33\%. Here, $p=15$ and $n=12$, which denotes the number of experts and the number of criteria, respectively.
4.3. Compromise Ranking by VIKOR. After the derivations of weights being associated with the criterion, six 3DP based RP service providers are ranked. For each provider, the performance scores versus each criterion were graded by the fifteen experts. The average score versus each criterion is demonstrated in Table 6(a). Then, the VIKOR technique being introduced for compromise ranking is applied after the criterion weights being calculated by DNP in Section 4.2. Supplier A got the high value, 3.952. Therefore, Supplier $A$ is the most suitable vendor. Table 6(b) demonstrates the compromise ranking of mold suppliers by VIKOR.

\section{Discussion}

The emergence of the 3DP will influence some particular sectors (e.g., animation and gaining as well as crafts and hobby sectors [7]) of the manufacturing industry significantly, especially from the aspect of supply-chain management. The 3DP has also been adopted by specific firms in the newproduct development RP processes. In the following Section, managerial implications will be discussed. Future research possibilities will also be discussed from both the industry and firm aspects.

5.1. Industry-Level Managerial Implications. The emergence of the 3DP influences the future of manufacturing significantly. The major influences will be from the aspects $[6,75]$, including (1) time to market, (2) product capabilities, (3) design openness, (4) customization, and (5) economics of offshore production, as well as (6) inexpensive production cost for a limited-quantity number of goods. The aspects will be discussed further.

(1) Time to Market. In recent years, the 3DP has come to the fore as a very competitive process in terms of cost and speed, and sales of related equipment have increased significantly compared to other RP machines [76]. Therefore, from the aspect of time to market, the 3DP based RP shortens both 
TABLE 6: (a) The average performance scores for each supplier. (b) Compromise ranking results by VIKOR.

(a)

\begin{tabular}{lcccccc}
\hline \multirow{2}{*}{ Criterion } & \multicolumn{6}{c}{ Supplier } \\
& $\mathrm{A}$ & $\mathrm{B}$ & $\mathrm{C}$ & $\mathrm{D}$ & $\mathrm{E}$ & $\mathrm{F}$ \\
\hline CPM & 4.333 & 3.778 & 3.818 & 3.100 & 3.333 & 4.000 \\
MHL & 4.000 & 3.667 & 3.273 & 3.000 & 3.333 & 3.333 \\
MPD & 4.556 & 3.778 & 3.273 & 3.000 & 2.667 & 3.333 \\
RPE & 4.222 & 4.111 & 3.818 & 3.500 & 3.667 & 4.000 \\
PNT & 3.667 & 3.778 & 3.636 & 3.100 & 3.333 & 3.667 \\
TQS & 4.222 & 3.889 & 3.636 & 2.800 & 3.000 & 3.667 \\
PME & 4.000 & 4.222 & 3.727 & 3.200 & 3.333 & 3.333 \\
PMT & 3.778 & 4.000 & 3.455 & 3.300 & 3.000 & 3.667 \\
QIT & 3.333 & 3.556 & 3.455 & 3.500 & 3.000 & 3.333 \\
FAE & 4.111 & 3.333 & 3.273 & 3.300 & 3.000 & 3.333 \\
MDC & 3.778 & 3.556 & 3.545 & 3.100 & 3.333 & 3.667 \\
FUS & 3.111 & 2.889 & 3.455 & 2.700 & 3.667 & 3.333 \\
\hline
\end{tabular}

(b)

\begin{tabular}{lcccccc}
\hline \multirow{2}{*}{ Criterion } & \multicolumn{7}{c}{ Supplier } \\
& $\mathrm{A}$ & $\mathrm{B}$ & $\mathrm{C}$ & $\mathrm{D}$ & $\mathrm{E}$ & $\mathrm{F}$ \\
\hline CPM & 0.406 & 0.354 & 0.358 & 0.291 & 0.313 & 0.375 \\
MHL & 0.301 & 0.276 & 0.246 & 0.226 & 0.251 & 0.251 \\
MPD & 0.418 & 0.347 & 0.301 & 0.275 & 0.245 & 0.306 \\
RPE & 0.366 & 0.356 & 0.331 & 0.303 & 0.318 & 0.346 \\
PNT & 0.274 & 0.283 & 0.272 & 0.232 & 0.249 & 0.274 \\
TQS & 0.393 & 0.362 & 0.338 & 0.260 & 0.279 & 0.341 \\
PME & 0.342 & 0.361 & 0.319 & 0.274 & 0.285 & 0.285 \\
PMT & 0.316 & 0.334 & 0.289 & 0.276 & 0.251 & 0.306 \\
QIT & 0.241 & 0.257 & 0.250 & 0.253 & 0.217 & 0.241 \\
FAE & 0.323 & 0.262 & 0.257 & 0.259 & 0.236 & 0.262 \\
MDC & 0.335 & 0.315 & 0.314 & 0.275 & 0.295 & 0.325 \\
FUS & 0.237 & 0.220 & 0.263 & 0.205 & 0.279 & 0.253 \\
\hline Sum & 3.952 & 3.727 & 3.537 & 3.130 & 3.217 & 3.567 \\
VIKOR & 1.000 & 0.943 & 0.895 & 0.792 & 0.814 & 0.903 \\
Rank & 1 & 2 & 4 & 6 & 5 & 3 \\
\hline
\end{tabular}

the time of prototyping as well as the product development time in comparison to the RP based on other methods. Bernstein and Farrington [77] further forecasted that the combination of $3 \mathrm{D}$ printing with manufacturing may result in new manufacturing models. The convergence of three factors, including e-commerce, just-in-time manufacturing bolstered by $3 \mathrm{DP}$, and predictive algorithms for market behavior, will result in a more anticipatory model of manufacturing and new-product development, which can quickly produce goods for small markets in order to test which products will be successful on a larger scale [77].

(2) Product Capabilities. 3DP materials are usually classified according to the material used, such as plastics, metals, ceramics, and others; all these 3DP materials have their individual uses, performance, capability, and cost [78]. 3DP materials are highly flexible and strong materials that come with unlimited printing capabilities that range from toys to metal guns, spare parts to automobiles, electronics to satellites, and dental crowns to the human heart [78]. Therefore, the products incorporating components being fabricated by 3DP will demonstrate distinct competitive advantages due to the superior features such as being smaller, lighter, stronger, less mechanically complex, and easier to maintain [75].

(3) Design Openness. With increasing standards of living everyone expects to use something unique; this demand can be accessed with the revolutionary 3DP technology where designs are limited to the designer's imagination [78]. Based on the 3DP technology, end users may design their own products easily. The open-designed products by end users and fabricated by using the 3DP can be differentiated from the mass-produced ones.

(4) Customization. 3DP is used to create customized, improved, and sometimes even impossible-to-manufacture products economically [75]. The fully customized products can be provided by vendors easily based on the 3DP technology. Therefore, the 3DP is heralding a new era of mass personalization [79]. The 3DP material revolution helped access mass customization [78], the ability to provide individually designed products, and services to every customer through high process agility, flexibility, and integration [80, 81]. For example, Nokia has released the 3D designs for the shells of Lumia 520/820 so that owners can customize the shells [82].

(5) Economics of Offshore Production. The traditional advantages of offshore production will also be challenged by the 3DP which can provide the just-in-time manufacturing near the point of sale or point of assembly [75]. Therefore, offshore production is increasingly moving back to rich countries because companies now want to be closer to their customers so that they can respond more quickly to changes in demand [3].

(6) Inexpensive Production Cost for a Limited-Quantity Number of Goods. Finally, one of the major characteristics or advantages of $3 \mathrm{DP}$ is that a low number of goods can be produced at an inexpensive cost, as compared to conventional manufacturing, which typically requires higher volumes to lower costs [6]. However, as that economy of scale comes into play, traditional manufacturing can be more beneficial for producing larger quantities of products. Figure 3 below illustrates a comparison of the costs of producing goods through traditional manufacturing methods versus 3DP [6].

Research works being related to the above-mentioned $3 \mathrm{DP}$ issues are still very limited. The researches worth further investigations, especially from the aspects of the fusion of mass customization and 3DP, the influences of 3DP on the reshoring, the supply-chain management in the era of 3DP, and so forth.

5.2. Firm-Level Managerial Implications for 3DP Based RP. The 3DP based RP services are very critical for the name branded IT products in the new product development process. This study mainly advanced the field of 3DP 


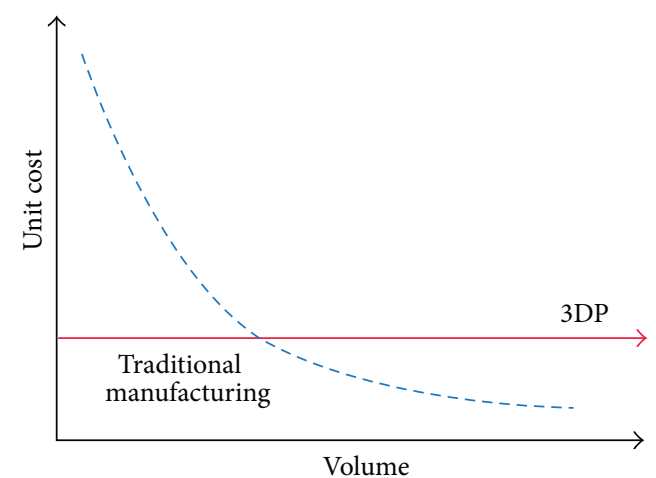

FIGURE 3: Production volume versus cost from the aspects of traditional manufacturing and the 3DP. Source: [6].

based RP service provider selection perspectives. First, an HMCDM framework has been proposed for 3DP based RP supplier selections, which has been verified as effective through verification by mechanical design experts. Second, the traditional hard-to-define 3DP based RP service provider improvement strategy problem was resolved based on the HMCDM approach being proposed. Finally, the proposed analytic framework can be leveraged for resolving 3DP based RP supplier selection and improvement problems as well as other MCDM-nature problems. Following, the managerial implications will be discussed.

According to Section 4.2, the most important three criteria include (1) the CPM in the MC aspect, (2) the TQS in the QC aspect, and (3) the MPD in the MC aspect. The weights being associated with the criteria are 0.094, 0.093, and 0.093, respectively. Therefore, TQS, MPD, and CPM are the most important factors in evaluating the 3DP based RP service providers. The empirical study results are consistent with the actual situation. The empirical study object is the name branded IT companies. For such firms, 3DP service suppliers need to communicate without problems (CPM) and provide a high quality (TQS) and stable supply of plenty prototypes (MPD) being required for the concept verifications in the new product development. Therefore, quality assurance and management capability aspects are prioritized in this survey. This phenomenon meets the actual situation.

Table 6(b) demonstrates the compromise ranking of each 3DP based RP service supplier. Supplier A is the most suitable mold supplier. In addition to PNT, PME, PMT, QIT, and FUS, the other criteria are the best.

Regarding the compromise ranking results of the 3DP based RP service providers, albeit Supplier A is the more suitable service provider than others based on the VIKOR results in Section 4.3; the services being provided by Supplier A have not reached the aspire level and can be enhanced further. Therefore, Supplier A can still be enhanced from following aspects: PNT (the plan for new technology introductions), PMT (precision measurement tool), MDC (capabilities to realize design changes by customers), and FUS (provision of free, urgency, and shortage samples) (refer to Table 7).

For other service providers, since many new concept development and testing as well as RP projects are needed for various product lines, one 3DP based RP service provider
TABLE 7: Criterion which can be enhanced to reach the aspiration level.

\begin{tabular}{lllllll}
\hline \multirow{2}{*}{ Criterion } & \multicolumn{7}{c}{ Supplier } \\
& A & B & C & D & E & F \\
\hline CPM & & $\checkmark$ & $\checkmark$ & $\checkmark$ & $\checkmark$ & $\checkmark$ \\
MHL & & $\checkmark$ & $\checkmark$ & $\checkmark$ & & \\
MPD & & $\checkmark$ & $\checkmark$ & $\checkmark$ & $\checkmark$ & $\checkmark$ \\
RPE & & $\checkmark$ & $\checkmark$ & $\checkmark$ & $\checkmark$ & $\checkmark$ \\
PNT & $\checkmark$ & & & & & \\
TQS & & $\checkmark$ & $\checkmark$ & $\checkmark$ & $\checkmark$ & $\checkmark$ \\
PME & & & & & & \\
PMT & $\checkmark$ & & $\checkmark$ & $\checkmark$ & $\checkmark$ & $\checkmark$ \\
QIT & & & & & & \\
FAE & & & & & & \\
MDC & $\checkmark$ & & & & & \\
FUS & $\checkmark$ & & & &
\end{tabular}

Remark: the column being checked implies the criterion which can be enhanced further to reach the aspiration level.

may not be able to fulfill the needs from new product development projects. Therefore, the name branded IT vendor usually includes all the service providers as vendors and classifies them into three classes and asks them to provide services with various requirements for precision, delivery time, and so forth. Service providers other than Supplier A should also be enhanced.

Based on the compromise ranking results based on VIKOR, Supplier A (ranked as number 1) and Supplier B (ranked as number 2) were classified as Class A. Supplier F (ranked as number 3) and Supplier C (ranked as number 4) were classified as Class B. Supplier E (ranked as number 5) and Supplier D (ranked as number 6) were classified as Class C. The VIKOR results demonstrate that Supplier C can be improved in the capabilities including CPM, MHL, MPD, RPE, TQS, and PMT. Supplier F can be improved in the capabilities including CPM, MPD, RPE, TQS, and PMT. Supplier $\mathrm{E}$ can be improved in the capabilities including CPM, MPD, RPE, TQS, and PMT. Finally, Supplier D can be improved in the capabilities including CPM, MHL, MPD, RPE, TQS, and PMT. The criteria which the service providers can enhance so as to achieve the aspiration level are summarized and demonstrated in Table 7.

For the firm specific issues, researches regarding how each criterion can influence the 3DP services for new product development are still very few. However, the influences can be very significant. Further investigations will be necessary to enhance the service quality and thus competitiveness of a 3DP based RP service provider. Meanwhile, how an IT firm in general and other firms which apply the 3DP based RP service will be influenced from the aspect of the criterion is also worth further investigations.

\section{Conclusions}

The 3DP is one of the most promising disruptive innovations in the past years which may change the world and drive 
the third industrial revolution. The emergence of 3DP may impact manufacturing, the industry, and the social change significantly. As the pricing of $3 \mathrm{D}$ printers is becoming affordable by small and medium enterprises, numerous 3DP based RP technology service providers are available now. How a suitable 3DP based RP service provider can be evaluated, selected, and enhanced has become one of the most critical issues for firms being engaged in new product developments. In this research, an HMCDM framework consisting of the DNP as well as VIKOR was proposed. Possible aspects and criteria being derived based on the literature review results were summarized by the modified Delphi method based on 16 mechanical mangers and 3DP service sales manager from the Taiwanese IT industry. Then, the decision problem structure was derived by DEMATEL based on experts' opinions. The weights being associated with the criteria were derived by using the DNP. Then, the compromise ranking of the service providers can be derived by VIKOR. Based on the empirical study results, the most important criteria include the total quality management system (TQS) and the capability of project management capabilities (CPM) in the management capability aspect. How the capabilities of the best service provider can be enhanced so as to achieve the aspiration level based on the VIKOR results was also demonstrated. The analytic framework can be used in selecting the most suitable 3DP based RP service providers. The evaluation results can be used to demonstrate the feasibility of the proposed framework. Meanwhile, the analytic framework can serve as the basis of future selections of 3DP based RP service providers.

\section{Conflict of Interests}

The authors declare that there is no conflict of interests regarding the publication of this paper.

\section{Acknowledgments}

The authors gratefully acknowledge the long term advices by distinguished Chair Professor, Dr. Gwo-Hshiung Tzeng on the research methods manipulations and analytic framework development. Meanwhile, the advices by Professor ChingTer Chang, the guest editor of the special issue of the Mathematical Problems in Engineering, on the enhancement of the original draft, the constructive criticism by reviewers, the assistances on the literature collections by Miss Qi Lu and Mr. Hsueh-Hsin Lu of the Institute of Industrial Education, National Taiwan Normal University, and the support of Taiwan National Science Council through Grant nos. NSC1002221-E-003-023 and NSC102-2511-S-003-061-MY3 are greatly appreciated.

\section{References}

[1] R. A. D'Aveni, "3-D printing will change the world," Harvard Business Review, vol. 91, pp. 34-35, 2013.

[2] The Economist, "3D printing: the printed world," The Economist, 2011.
[3] P. Markillie, “The third industrial revolution," The Economist, 2012.

[4] I. M. Hutchings and G. D. Martin, Inkjet Technology for Digital Fabrication, Wiley, 2012.

[5] J. Manyika, M. Chui, J. Bughin, R. Dobbs, P. Bisson, and A. Marrs, Disruptive Technologies: Advances that will Transform Life, Business, and the Global Economy, McKinsey Global Institute, 2013.

[6] B. Grynol, Disruptive Manufacturing-The Effects of 3D Printing, Deloitte LLP, Ontario, Canada, 2013.

[7] S. Faktor, "How HP Could Reinvent 3D Printing," http://www .forbes.com/sites/stevefaktor/2012/10/15/how-hp-could-reinvent-3d-printing-and-itself/2/.

[8] D. Kochan, C. C. Kai, and D. Zhaohui, "Rapid prototyping issues in the 21st century," Computers in Industry, vol. 39, no. 1, pp. 3$10,1999$.

[9] S. S. Gill and M. Kaplas, "Comparative study of 3D printing technologies for rapid casting of aluminium alloy," Materials and Manufacturing Processes, vol. 24, no. 12, pp. 1405-1411, 2009.

[10] M. Burns, Automated Fabrication: Improving Productivity in Manufacturing, Prenrice Hall, 1993.

[11] P. F. Jacobs, Rapid Prototyping \& Manufacturing: Fundamentals of Stereolithography, Society of Manufacturing Engineers, 1992.

[12] I. Gibson, D. W. Rosen, and B. Stucker, Additive Manufacturing Technologies: Rapid Prototyping to Direct Digital Manufacturing, Springer, 2009.

[13] N. Hopkinson and P. Dickens, "Rapid prototyping for direct manufacture," Rapid Prototyping Journal, vol. 7, no. 4, pp. 197202, 2001.

[14] T. Wohlers, Rapid Prototyping, Tooling, and Manufacturing: State of the Industry, Annual Worldwide Progress Report, Wohlers Associates, Fort Collins, Colo, USA, 2003.

[15] A. Butscher, M. Bohner, S. Hofmann, L. Gauckler, and R. Müller, "Structural and material approaches for bone tissue engineering in powder based 3D printing," in Powder Based Three-Dimensional Printing of Calcium Phosphate Structures for Scaffold Engineering, vol. 7, p. 14, 2013.

[16] K. Lu and W. T. Reynolds, "3DP process for fine mesh structure printing," Powder Technology, vol. 187, no. 1, pp. 11-18, 2008.

[17] A. Butscher, M. Bohner, S. Hofmann, L. Gauckler, and R. Müller, "Structural and material approaches to bone tissue engineering in powder-based three-dimensional printing," Acta Biomaterialia, vol. 7, no. 3, pp. 907-920, 2011.

[18] R. van Noort, "The future of dental devices is digital, Dental Materials, vol. 28, no. 1, pp. 3-12, 2012.

[19] S. Bradshaw, A. Bowyer, and P. Haufe, "The intellectual property implications of low-cost 3D printing," Scripted, vol. 7, pp. 5-31, 2010.

[20] H. Lipson and M. Kurman, Fabricated: The New World of $3 D$ Printing, Wiley, 2013.

[21] D. Roberts, The Innovator's Sourcebook, West Fulton Media, Chicago, Ill, USA, 2010.

[22] C. K. Chua, K. F. Leong, and C. C. S. Lim, Rapid Prototyping: Principles and Applications, World Scientific, Singapore, 3rd edition, 2010.

[23] R. Budde, K. Kautz, K. Kuhlenkamp, and H. Züllighoven, Prototyping, Springer, 1992.

[24] C. C. Kai, L. K. Fai, and L. Chu-Sing, Rapid Prototyping: Principles and Applications in Manufacturing, World Scientific, River Edge, NJ, USA, 2003. 
[25] Z. Gosiewski and A. P. Koszewnik, "Fast prototyping method for the active vibration damping system of mechanical structures," Mechanical Systems and Signal Processing, vol. 36, pp. 136-151, 2013.

[26] D. Avola, M. Spezialetti, and G. Placidi, "Design of an efficient framework for fast prototyping of customized human-computer interfaces and virtual environments for rehabilitation," Computer Methods and Programs in Biomedicine, vol. 110, pp. 490502,2013

[27] A. Ziviani, T. B. Cardozo, and A. T. A. Gomes, "Rapid prototyping of active measurement tools," Computer Networks, vol. 56, no. 2, pp. 870-883, 2012.

[28] J. Do, J. Y. Zhang, and C. M. Klapperich, "Maskless writing of microfluidics: rapid prototyping of $3 \mathrm{D}$ microfluidics using scratch on a polymer substrate," Robotics and ComputerIntegrated Manufacturing, vol. 27, no. 2, pp. 245-248, 2011.

[29] M. Eisenberg, "3D printing for children: what to build next?" International Journal of Child-Computer Interaction, vol. 1, pp. 7-13, 2012.

[30] L. Casey, "Prototypes pronto," Packaging Digest, vol. 46, no. 8, pp. 54-56, 2009.

[31] P. K. Venuvinod and W. Ma, Rapid Prototyping: Laser-Based and Other Technologies, Springer, 2004.

[32] E. Bassoli, A. Gatto, L. Iuliano, and M. G. Violante, "3D printing technique applied to rapid casting," Rapid Prototyping Journal, vol. 13, no. 3, pp. 148-155, 2007.

[33] S. A. Panëels, P. D. Ritsos, P. J. Rodgers, and J. C. Roberts, "Prototyping 3D haptic data visualizations," Computers \& Graphics, vol. 37, pp. 179-192, 2013.

[34] A. D. P. Henriksen, "A technology assessment primer for management of technology," International Journal of Technology Management, vol. 13, no. 5-6, pp. 615-638, 1997.

[35] A. Drejer and J. O. Riis, "Competence development and technology: how learning and technology can be meaningfully integrated," Technovation, vol. 19, no. 10, pp. 631-644, 1999.

[36] M. Torkkeli and M. Tuominen, "The contribution of technology selection to core competencies," International Journal of Production Economics, vol. 77, no. 3, pp. 271-284, 2002.

[37] A. L. Porter and M. J. Detampel, “Technology opportunities analysis," Technological Forecasting and Social Change, vol. 49, no. 3, pp. 237-255, 1995.

[38] T. M. Khalil, Management of Technology, Tata McGraw-Hill Education, 2009.

[39] C.-Y. Huang, Y.-H. Hung, and G.-H. Tzeng, "Using hybrid MCDM methods to assess fuel cell technology for the next generation of hybrid power automobiles," Journal of Advanced Computational Intelligence and Intelligent Informatics, vol. 15, no. 4, pp. 406-417, 2011.

[40] N. Dalkey and O. Helmer, "An experimental application of the Delphi method to the use of experts," Management Science, vol. 9, pp. 458-467, 1963.

[41] J. W. Murry and J. O. Hammons, "Delphi: a versatile methodology for conducting qualitative research," The Review of Higher Education, vol. 18, pp. 423-436, 1995.

[42] W. C. Sung, "Application of Delphi method, a qualitative and quantitative analysis, to the healthcare management," Journal of Healthcare Management, vol. 2, pp. 11-19, 2001.

[43] Y. S. Lee, J. C. Huang, and Y. S. Hsu, "Using modified delphi method to explore the competition strategy for software companies of Taiwan," Journal of Informatics \& Electronics, vol. 13, pp. 39-50, 2008.
[44] J. Jones and D. Hunter, "Consensus methods for medical and health services research," British Medical Journal, vol. 311, no. 7001, pp. 376-380, 1995.

[45] C.-Y. Huang, J. Z. Shyu, and G.-H. Tzeng, "Reconfiguring the innovation policy portfolios for Taiwan's SIP Mall industry," Technovation, vol. 27, no. 12, pp. 744-765, 2007.

[46] C.-Y. Huang, G.-H. Tzeng, Y.-T. Chen, and H. Chen, "Performance evaluation of leading fabless integrated circuit design houses by using a multiple objective programming based data envelopment analysis approach," International Journal of Innovative Computing Information and Control, vol. 8, pp. 58995916, 2012.

[47] H. A. Linstone and M. Turoff, The Delphi Method: Techniques and Applications, Addison-Wesley, Reading, Mass, USA, 1975.

[48] N. C. Dalkey, "The Delphi method: an experimental application of group opinion," in Studies in the Quality of Life: Delphi and Decision-Making, N. C. Dalkey, D. Rourke, R. Lewis, and D. Snyder, Eds., Lexington Books, Lexington, Mass, USA, 1972.

[49] R. C. Judd, "Forecasting to consensus gathering: delphi grows up to college needs," College and University Business, vol. 53, pp. 35-38, 1972.

[50] K. W. Brooks, "Delphi Technique: expanding applications," North Central Association Quarterly, vol. 54, pp. 377-385, 1979.

[51] C.-H. Liu, G.-H. Tzeng, and M.-H. Lee, "Improving tourism policy implementation-the use of hybrid MCDM models," Tourism Management, vol. 33, no. 2, pp. 413-426, 2012.

[52] G. Phillips-Wren, L. C. Jain, K. Nakamatsu, and R. J. Howlett, "Advances in intelligent decision technologies," in Proceedings of the 2nd Kes International Symposium Idt, Springer, 2010.

[53] A. Gabus and E. Fontela, World Problems, an Invitation to Further thought within the Framework of DEMATEL, Batelle Geneva Research Center, Geneva, Switzerland, 1972.

[54] C.-Y. Huang and J. Z. Shyu, "Developing e-commerce business models for enabling silicon intellectual property transactions," International Journal of Information Technology and Management, vol. 5, no. 2-3, pp. 114-133, 2006.

[55] C.-Y. Huang, G.-H. Tzeng, and W.-R. J. Ho, "System on chip design service e-business value maximization through a novel MCDM framework," Expert Systems with Applications, vol. 38, no. 7, pp. 7947-7962, 2011.

[56] G.-H. Tzeng and C.-Y. Huang, "Combined DEMATEL technique with hybrid MCDM methods for creating the aspired intelligent global manufacturing \& logistics systems," Annals of Operations Research, vol. 197, pp. 159-190, 2012.

[57] T. L. Saaty, The Analytic Hierarchy Process: Planning, Priority Setting, Resource Allocation, McGraw-Hill International Book Co, 1980.

[58] M. Tamura, H. Nagata, and K. Akazawa, "Extraction and systems analysis of factors that prevent safety and security by structural models," in Proceedings of the 41st SICE Annual Conference, vol. 3, pp. 1752-1759, Osaka, Japan, 2002.

[59] M.-T. Lu, S.-W. Lin, and G.-H. Tzeng, "Improving RFID adoption in Taiwan's healthcare industry based on a DEMATEL technique with a hybrid MCDM model," Decision Support Systems, vol. 56, pp. 259-269, 2013.

[60] P.-L. Yu, "A class of solutions for group decision problems," Management Science, vol. 19, pp. 936-946, 1973.

[61] M. Zeleny and J. L. Cochrane, Multiple Criteria Decision Making, vol. 25, McGraw-Hill, New York, NY, USA, 1982.

[62] S. Opricovic and G.-H. Tzeng, "Fuzzy multicriteria model for postearthquake land-use planning," Natural Hazards Review, vol. 4, no. 2, pp. 59-64, 2003. 
[63] S. Opricovic, "Multicriteria optimization of civil engineering systems," Faculty of Civil Engineering, Belgrade, vol. 2, pp. 5-21, 1998.

[64] C.-L. Hwang and K. Yoon, Multiple Attribute Decision Making, Springer, 1981.

[65] K. Yoon, "A reconciliation among discrete compromise solutions," Journal of the Operational Research Society, vol. 38, no. 3, pp. 277-286, 1987.

[66] S. Opricovic and G.-H. Tzeng, "Multicriteria planning of postearthquake sustainable reconstruction," Computer-Aided Civil and Infrastructure Engineering, vol. 17, no. 3, pp. 211-220, 2002.

[67] G.-H. Tzeng, S.-H. Tsaur, Y.-D. Laiw, and S. Opricovic, "Multicriteria analysis of environmental quality in Taipei: public preferences and improvement strategies," Journal of Environmental Management, vol. 65, no. 2, pp. 109-120, 2002.

[68] S. Opricovic and G.-H. Tzeng, "Compromise solution by MCDM methods: a comparative analysis of VIKOR and TOPSIS," European Journal of Operational Research, vol. 156, no. 2, pp. 445-455, 2004.

[69] G.-H. Tzeng, C.-W. Lin, and S. Opricovic, "Multi-criteria analysis of alternative-fuel buses for public transportation," Energy Policy, vol. 33, no. 11, pp. 1373-1383, 2005.

[70] S. Opricovic and G.-H. Tzeng, "Extended VIKOR method in comparison with outranking methods," European Journal of Operational Research, vol. 178, no. 2, pp. 514-529, 2007.

[71] M. Freimer and P. L. Yu, "Some new results on compromise solutions for group decision problems," Management Science, vol. 22, no. 6, pp. 688-693, 1976.

[72] S. Upcraft and R. Fletcher, "The rapid prototyping technologies," Assembly Automation, vol. 23, no. 4, pp. 318-330, 2003.

[73] T.-J. Hsu and W.-H. Lai, "Manufacturing parts optimization in the three-dimensional printing process by the taguchi method," Journal of the Chinese Institute of Engineers, vol. 33, no. 1, pp. 121-130, 2010.

[74] J. Thilmany, "Printing in three dimensions," Mechanical Engineering, vol. 123, p. 58, 2001.

[75] V. Srinivasan and J. Bassan, 3D Printing and the Future of Manufacturing, Computer Sciences Corporation, 2012.

[76] T. T. Wohlers, Wohlers Report 2005, Rapid Prototyping, Tooling and Manufacturing: State of the Industry, Wohlers Associates, Fort Collins, Colo, USA, 2005.

[77] E. Bernstein and T. Farrington, Will 3-D Printing Cause Traditional Manufacturing to Collapse?vol. 2014, HBR Blog Network, 2014.

[78] MarketsandMarkets, 3D Printing Materials Market By Plastics (ABS, PLA, Nylon \& Others), By Metals (Steel, Titanium, Gold \& Others), By Ceramics (Silica, Glass \& Others), By Others (Laywood \& Others), By Forms \& By End-User IndustriesGlobal Trends \& Forecasts To 2018, MarketsandMarkets, Dallas, Tex, USA, 2013.

[79] C. Jewell, "3-D printing and the future of stuff," WIPO Magazine, pp. 2-6, 2013.

[80] S. M. Davis, "From "future perfect": mass customizing," Strategy \& Leadership, vol. 17, pp. 16-21, 1989.

[81] G. da Silveira, D. Borenstein, and F. S. Fogliatto, "Mass customization: literature review and research directions," International Journal of Production Economics, vol. 72, no. 1, pp. 1-13, 2001.

[82] Nokia, "3D print a shell for your Nokia Phone," 2013, http:// www.tcshelp.com. 


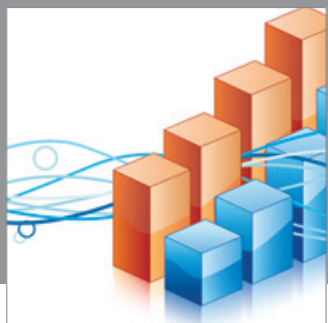

Advances in

Operations Research

mansans

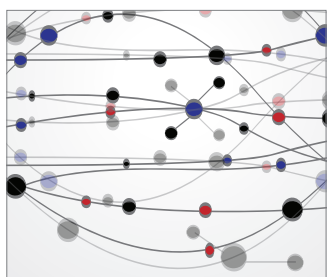

The Scientific World Journal
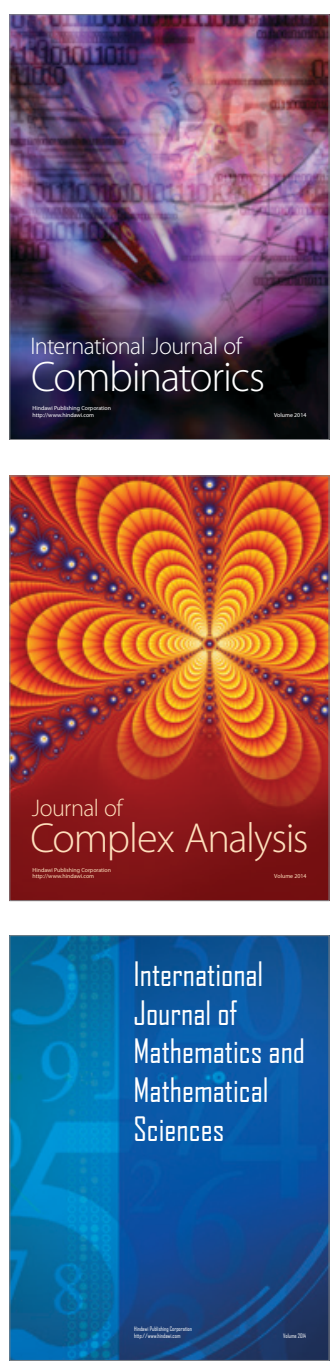
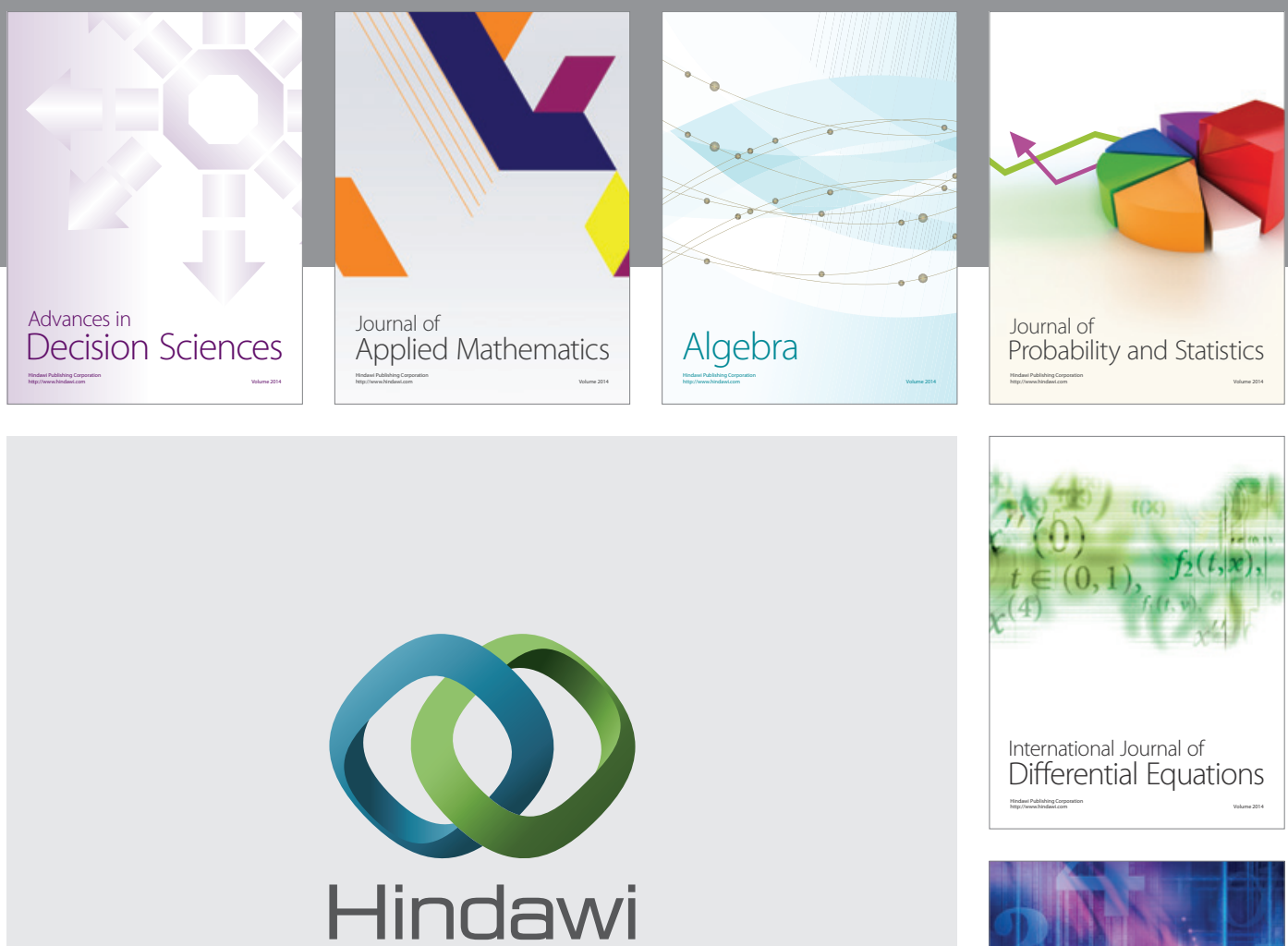

Submit your manuscripts at http://www.hindawi.com
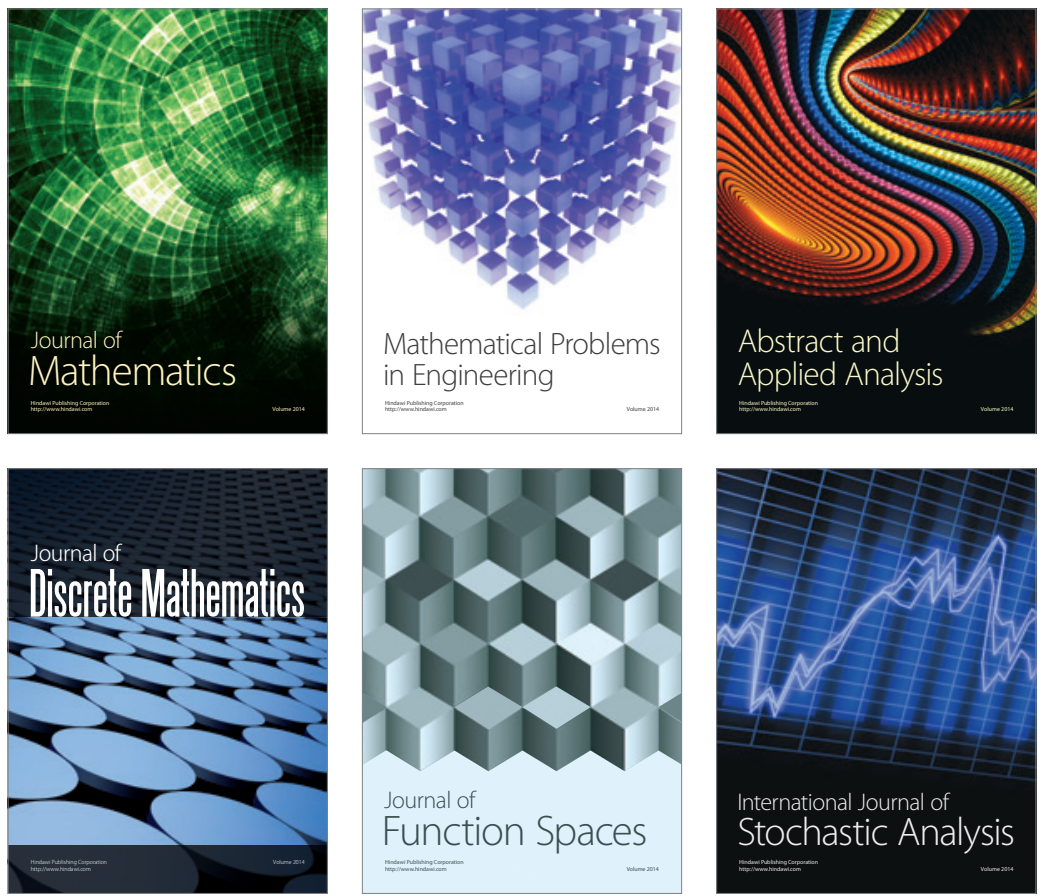

Journal of

Function Spaces

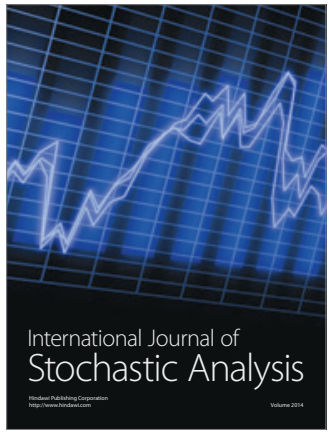

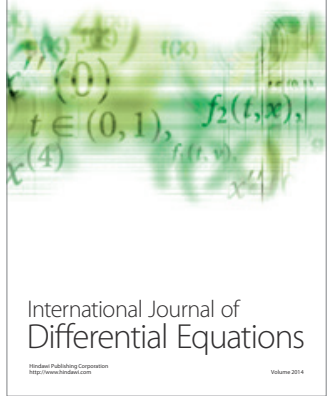
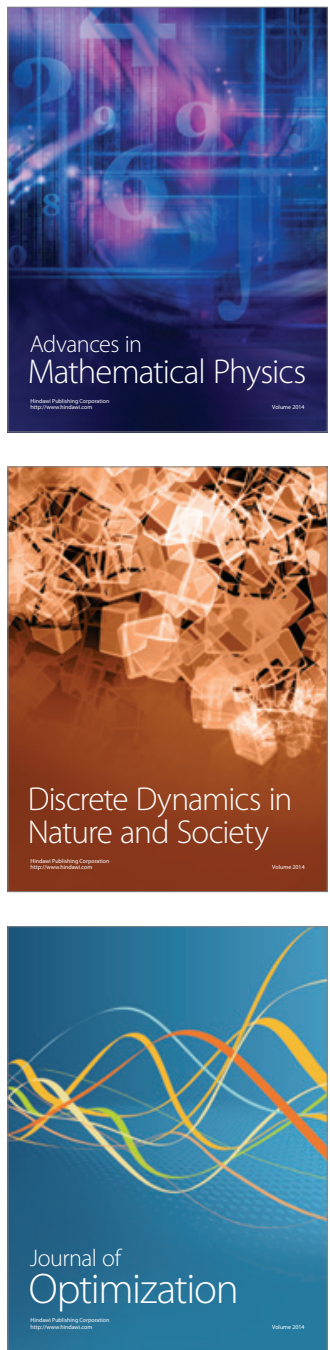